Abstracta Iranica Iranica

Revue bibliographique pour le domaine irano-aryen

Volume 28 | 2007

Comptes rendus des publications de 2005

\title{
«L'Iran, entre nation, islam et monde ». Etudes, mars 2005, pp. 309-319.
}

\section{Anicée Van Engeland}

\section{(2) OpenEdition}

1 Journals

\section{Édition électronique}

URL : http://journals.openedition.org/abstractairanica/19031

DOI : 10.4000/abstractairanica.19031

ISSN : 1961-960X

Éditeur :

CNRS (UMR 7528 Mondes iraniens et indiens), Éditions de l'IFRI

Édition imprimée

Date de publication : 15 mai 2007

ISSN : 0240-8910

Référence électronique

Anicée Van Engeland, « "L'Iran, entre nation, islam et monde ». Etudes, mars 2005, pp. 309-319. », Abstracta Iranica [En ligne], Volume 28 | 2007, document 421, mis en ligne le 18 septembre 2007, consulté le 25 septembre 2020. URL : http://journals.openedition.org/abstractairanica/19031 ; DOI : https://doi.org/10.4000/abstractairanica.19031

Ce document a été généré automatiquement le 25 septembre 2020.

Tous droits réservés 


\title{
« L'Iran, entre nation, islam et monde ». Etudes, mars 2005, pp. 309-319.
}

\author{
Anicée Van Engeland
}

1 L'A. évoque l'existence d'une nouvelle dialectique en Iran qui serait le résultat de la réalité politique, de l'isolement du pays et des transformations qu'ont subies la société et la culture iranienne. Cette nouvelle dialectique lie la société civile iranienne à la République islamique. Cette affirmation peut paraître étrange étant donné l'opposition de la société civile au système. L'A. explique néanmoins que ces rapports de forces peuvent s'expliquer aujourd'hui par une équation tradition contre modernité. Selon B. Hourcade la nouvelle identité iranienne se construit sur cette opposition mais aussi en combinant nation, islam et monde. Il est ainsi possible aujourd'hui grâce à ces combinaisons de revoir des concepts et analyses utilisés il y a trente ans et qui n'avaient pas permis de prévoir la révolution islamique.

INDEX

Thèmes : 13.1. Iran 
AUTEURS

ANICÉE VAN ENGELAND

Paris 